\title{
Surpporting information
}

\author{
A Robust Strategy for Engineering $\mathrm{Fe}_{7} \mathrm{~S}_{8} / \mathrm{C}$ Hybrid Nanocages Reinforced by \\ Defect-Rich $\mathrm{MoS}_{2}$ Nanosheets for Superior Potassium-Ion Storage \\ Wenda Li", Dezhu Wang\#, Zhijiang Gong, Zhengmao Yin, Xiaosong Guo, Jing Liu, \\ Changming Mao, Zhonghua Zhang* and Guicun $\mathrm{Li}^{*}$ \\ \# These authors contributed equally to this work. \\ College of Materials Science and Engineering, Qingdao University of Science and \\ Technology, Qingdao 266042, China \\ E-mail: zhangzh@qust.edu.cn; guicunli@qust.edu.cn
}




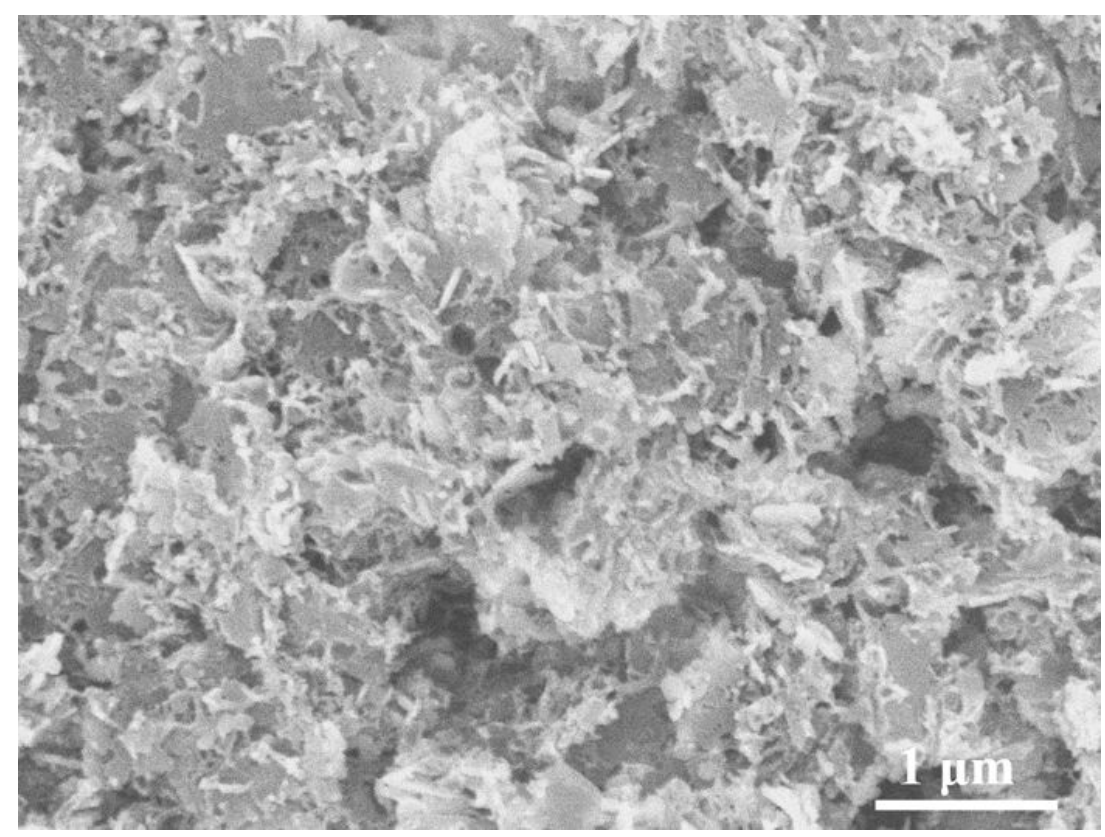

Fig. S1. The SEM image of $\mathrm{Fe}_{7} \mathrm{~S}_{8} / \mathrm{C}$ that directly derived from the sulfuration of Mil$88 \mathrm{~B}(\mathrm{Fe})$.

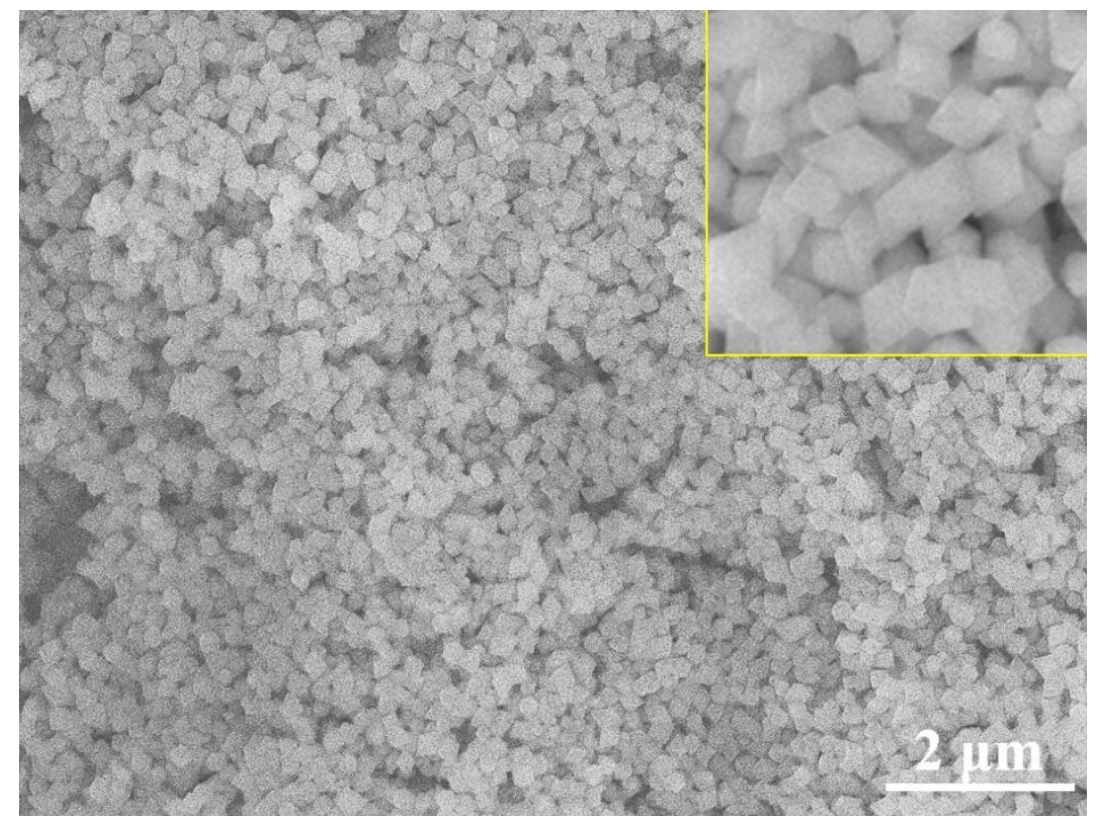

Fig. S2. The SEM image of Mil-88B(Fe). 


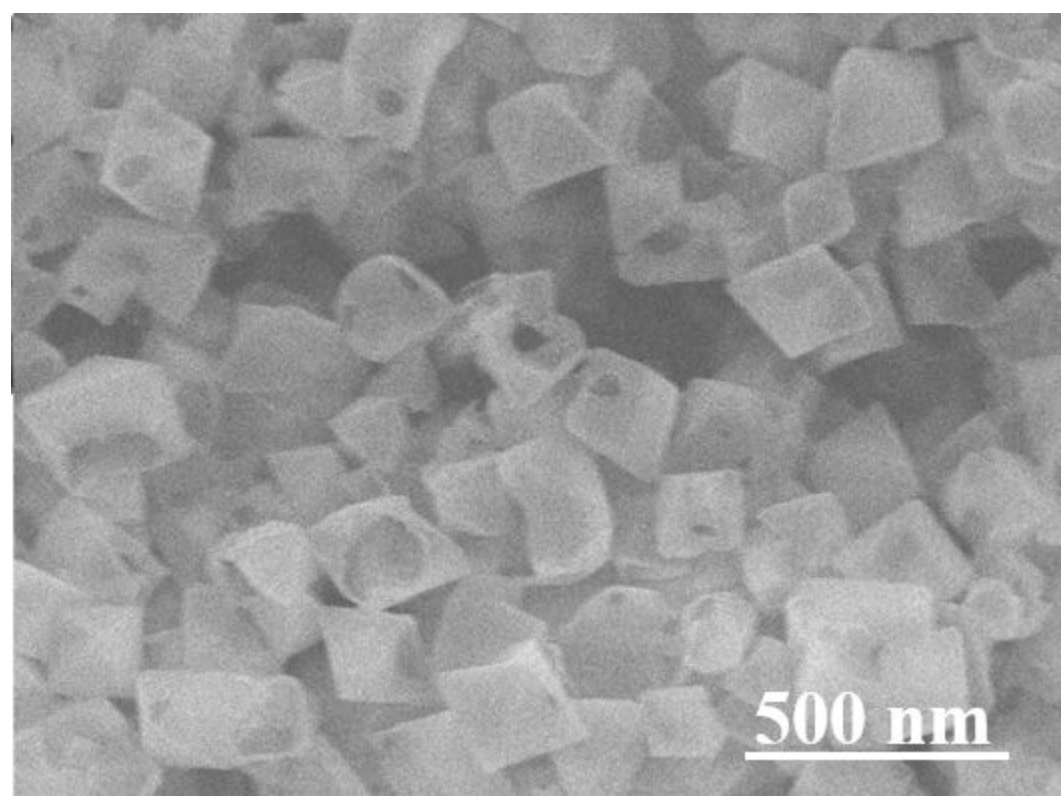

Fig. S3. The SEM image of TA-Mil-88B(Fe).
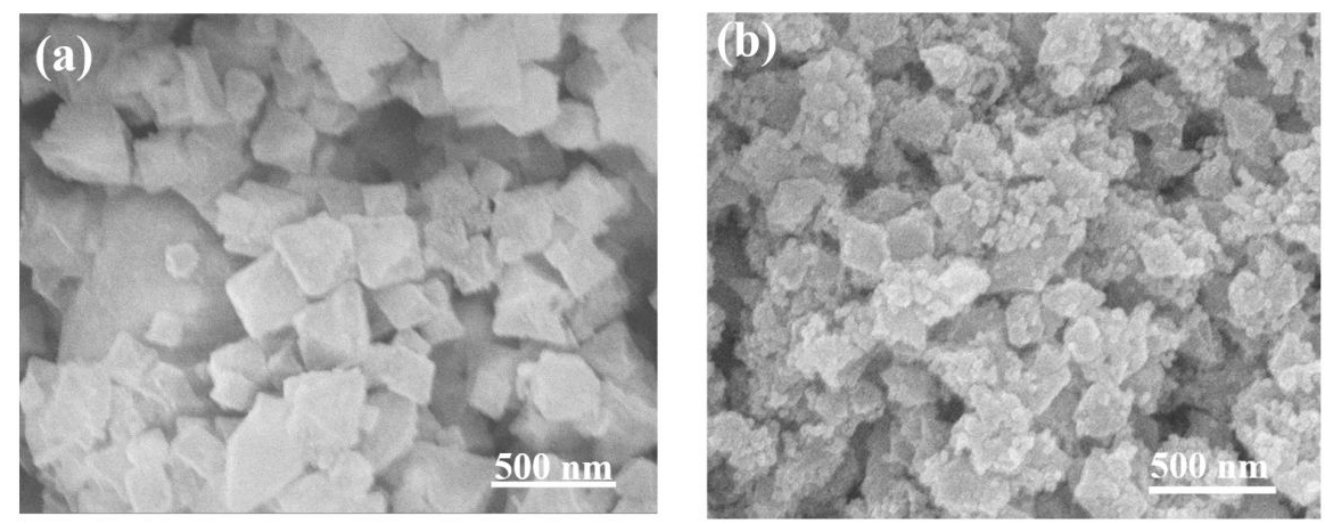

Fig. S4. SEM of the (a) $\mathrm{Fe}_{7} \mathrm{~S}_{8} / \mathrm{C} @ \mathrm{~d}-\mathrm{MoS}_{2}-\mathrm{I}$ and (b) $\mathrm{Fe}_{7} \mathrm{~S}_{8} / \mathrm{C} @ \mathrm{~d}-\mathrm{MoS}_{2}$-E composites; The $\mathrm{Fe}_{7} \mathrm{~S}_{8} / \mathrm{C} @ \mathrm{~d}-\mathrm{MoS}_{2}$ composites were prepared with POM precursor amount of 300 and $700 \mathrm{mg}$, respectively. Resultant specimens being labeled $\mathrm{Fe}_{7} \mathrm{~S}_{8} / \mathrm{C} @ \mathrm{~d}-\mathrm{MoS}_{2}-\mathrm{I}$ and $\mathrm{Fe}_{7} \mathrm{~S}_{8} / \mathrm{C} @ \mathrm{~d}-\mathrm{MoS}_{2}$-E composites. 


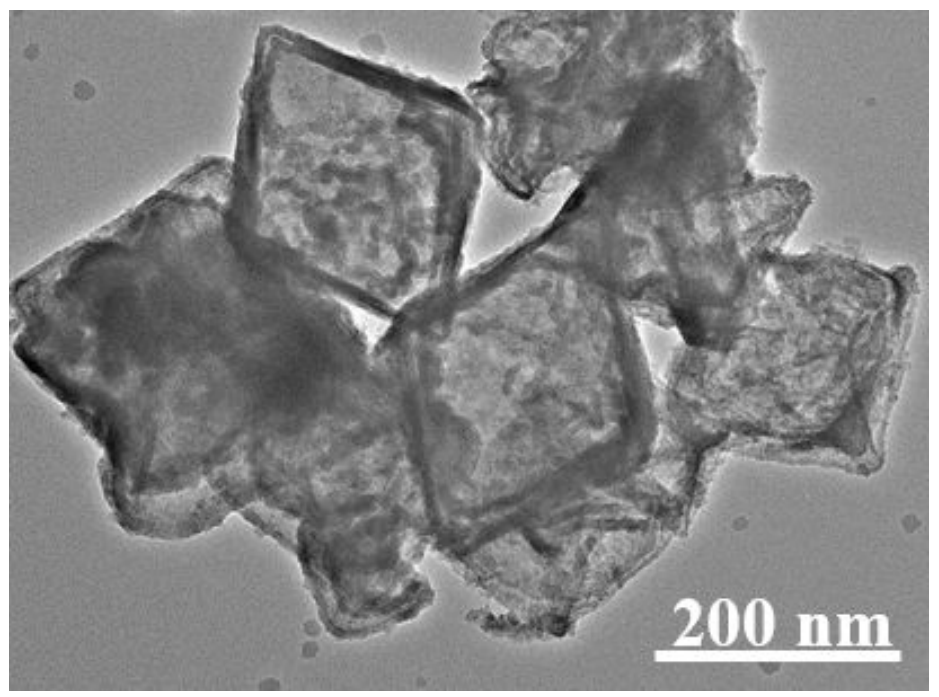

Fig. S5. The low magnification TEM image of $\mathrm{Fe}_{7} \mathrm{~S}_{8} @ \mathrm{C}$ nanocages.

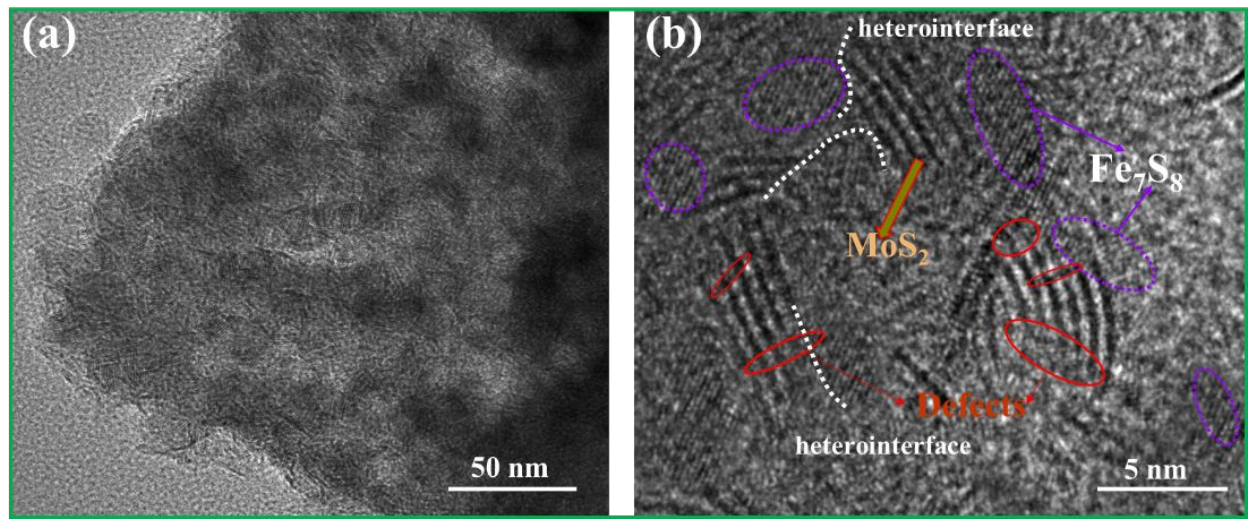

Fig. S6. TEM images (a) and HRTEM images of as-synthesized $\mathrm{Fe}_{7} \mathrm{~S}_{8} / \mathrm{C} @ \mathrm{~d}-\mathrm{MoS}_{2}$ composites. 


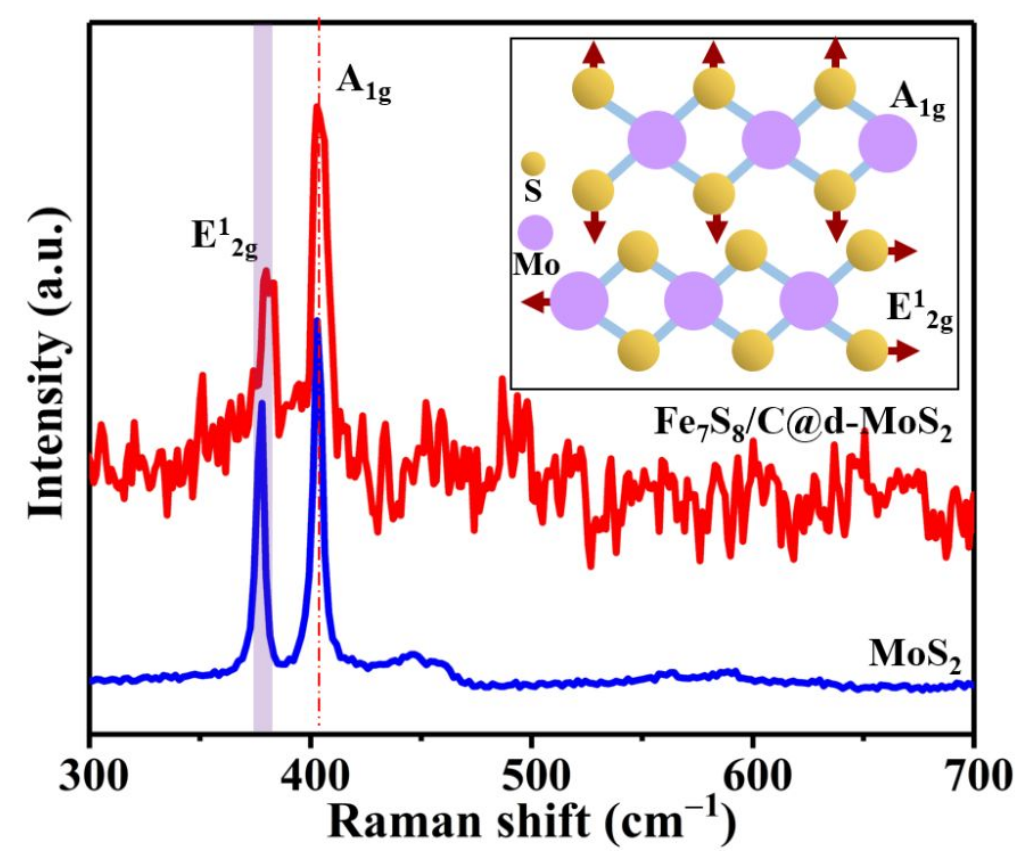

Fig. S7. Raman spectra curves of $\mathrm{Fe}_{7} \mathrm{~S}_{8} / \mathrm{C} @ \mathrm{~d}-\mathrm{MoS}_{2}$ and $\mathrm{MoS}_{2}$ samples.

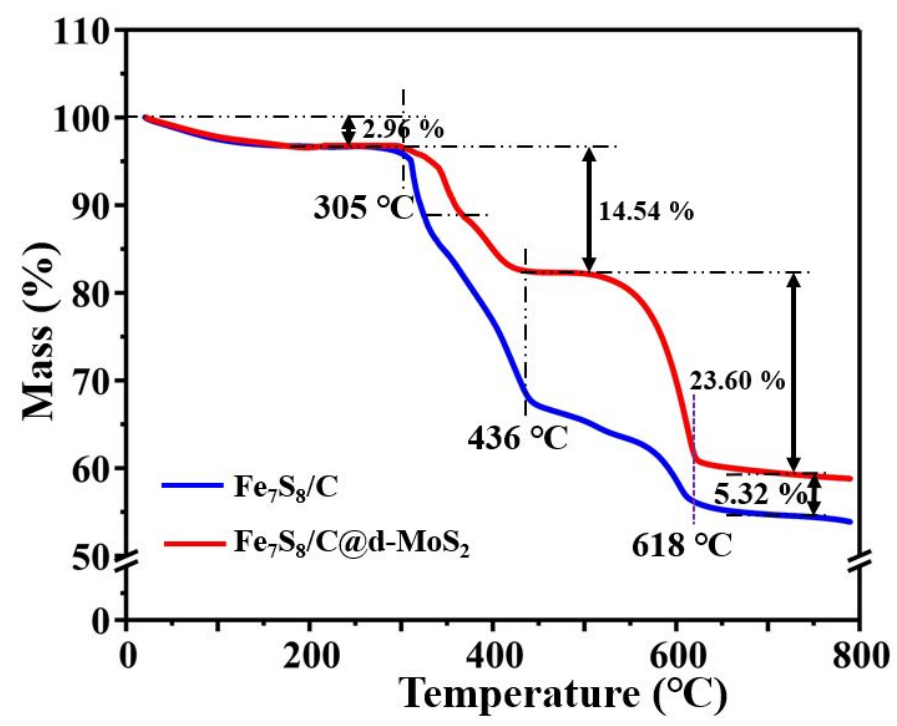

Fig. S8. TG curves of the $\mathrm{Fe}_{7} \mathrm{~S}_{8} / \mathrm{C} @ \mathrm{~d}-\mathrm{MoS}_{2}$ and $\mathrm{Fe}_{7} \mathrm{~S}_{8} / \mathrm{C}$ composites.

Table. S1 Elemental content of the $\mathrm{Fe}_{7} \mathrm{~S}_{8} / \mathrm{C} @ \mathrm{~d}-\mathrm{MoS}_{2}$ composites. 


\begin{tabular}{|c|c|c|c|c|c|}
\hline Sample & $\mathrm{C}($ wt.\%) & $\mathrm{N}($ wt.\%) & $\mathrm{S}($ wt.\%) & $\mathrm{Fe}($ wt.\%) & $\mathrm{Mo(wt. \% )}$ \\
\hline $\mathrm{Fe}_{7} \mathrm{~S}_{8} / \mathrm{C} @ \mathrm{~d}-\mathrm{MoS}_{2}$ & 35.8 & 3.1 & 25.9 & 19.7 & 14.5 \\
\hline
\end{tabular}
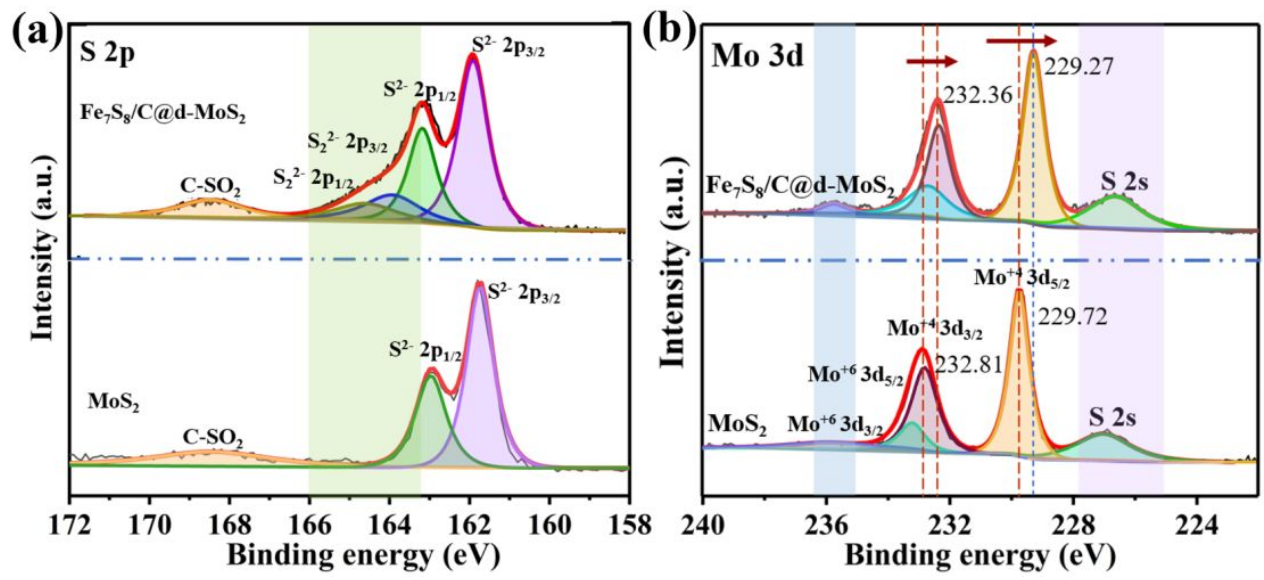

Fig. S9. High-resolution XPS spectra and the corresponding curves of (a) S 2p and (b) Mo 3d for $\mathrm{Fe}_{7} \mathrm{~S}_{8} / \mathrm{C} @ \mathrm{~d}-\mathrm{MoS}_{2}$ and $\mathrm{MoS}_{2}$.

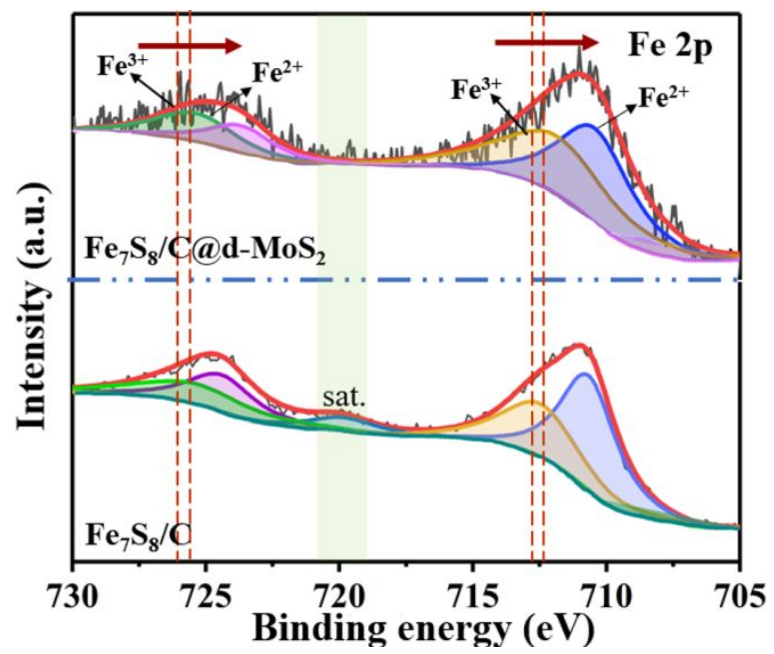

Fig. S10. High-resolution XPS spectra and the corresponding curves of Fe 2p for $\mathrm{Fe}_{7} \mathrm{~S}_{8} / \mathrm{C} @ \mathrm{~d}-\mathrm{MoS}_{2}$ and $\mathrm{Fe}_{7} \mathrm{~S}_{8} / \mathrm{C}$. 


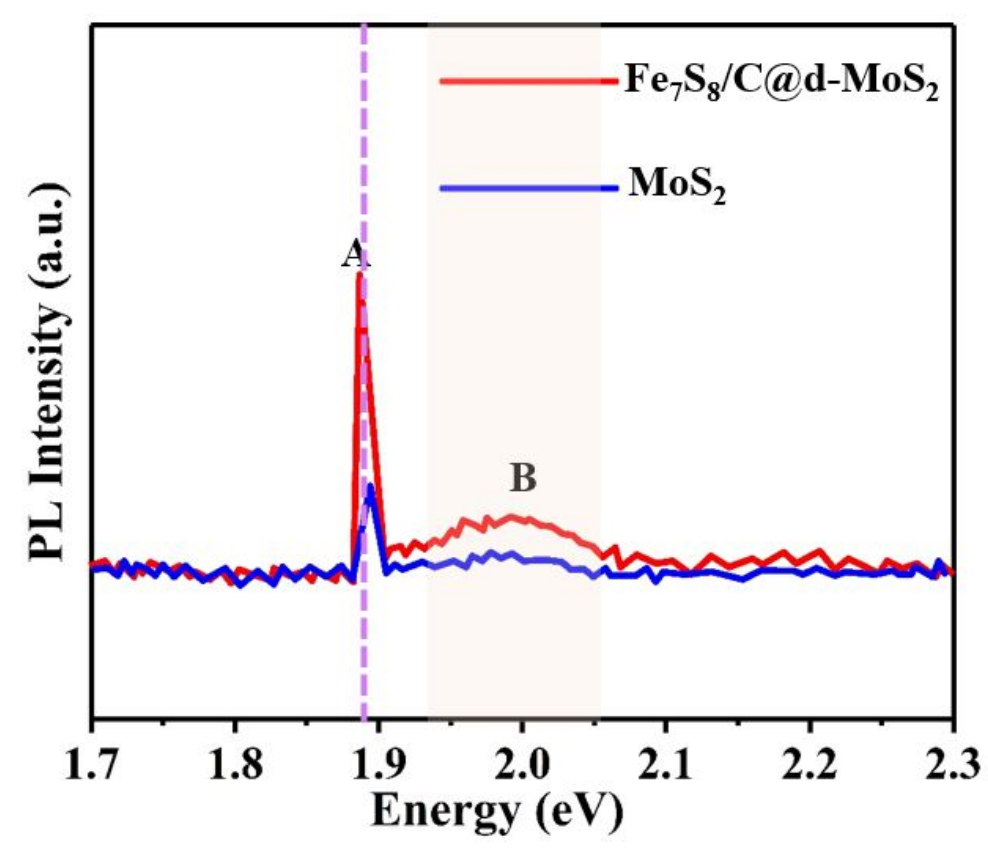

Fig. S11. PL spectra of the $\mathrm{Fe}_{7} \mathrm{~S}_{8} / \mathrm{C} @ \mathrm{~d}-\mathrm{MoS}_{2}$ and $\mathrm{MoS}_{2}$.

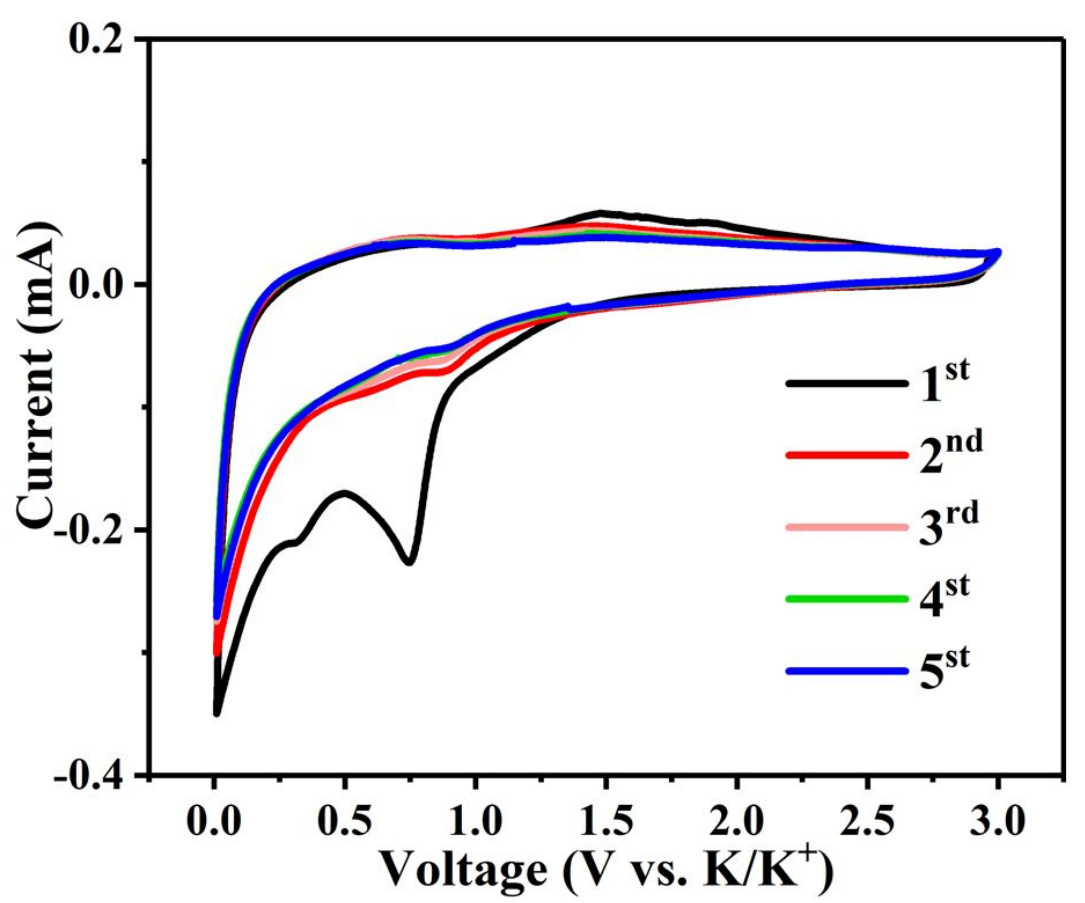

Fig. S12. CV curves of $\mathrm{Fe}_{7} \mathrm{~S}_{8} / \mathrm{C}$ electrode at a scan rate of $0.1 \mathrm{mV} \mathrm{s}^{-1}$ in the potential range of 0.01-3.0 V. 


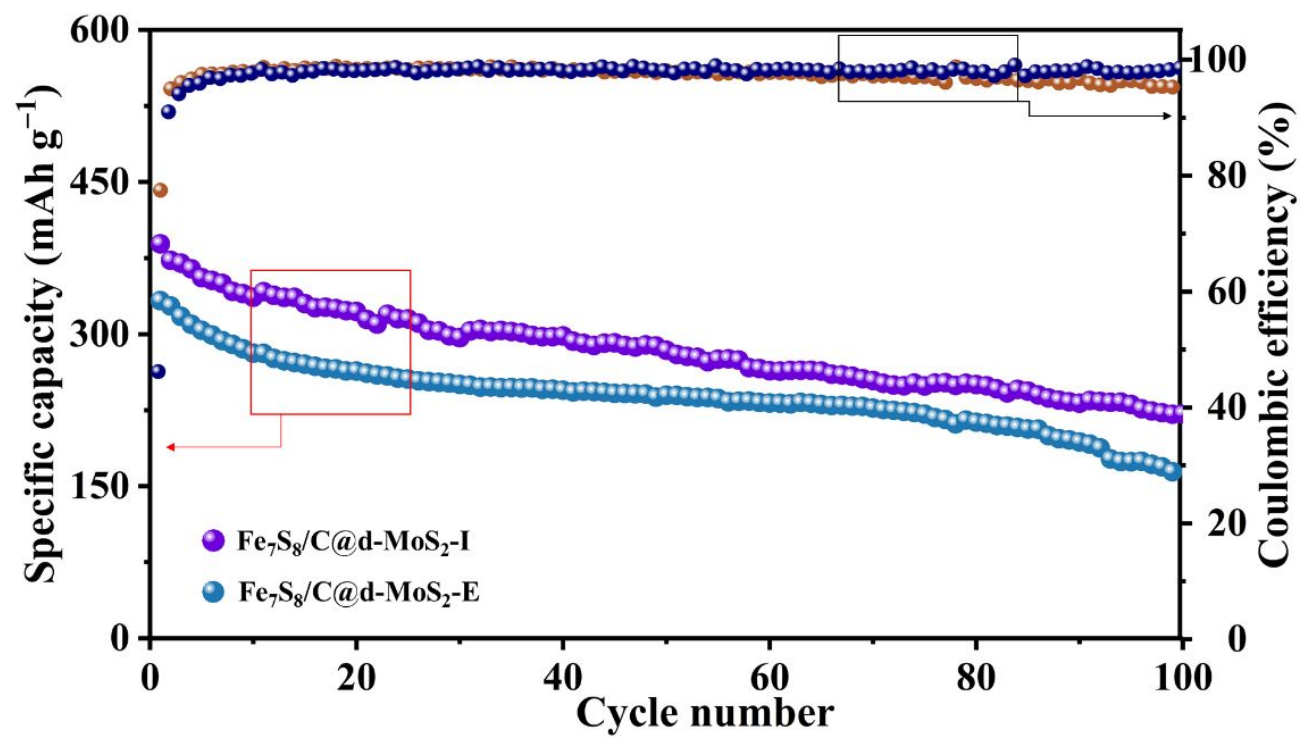

Fig. S13. Cycling performance $\mathrm{Fe}_{7} \mathrm{~S}_{8} / \mathrm{C} @ \mathrm{~d}-\mathrm{MoS}_{2}-\mathrm{I}$ and $\mathrm{Fe}_{7} \mathrm{~S}_{8} / \mathrm{C} @ \mathrm{~d}-\mathrm{MoS}_{2}-\mathrm{E}$ electrodes.

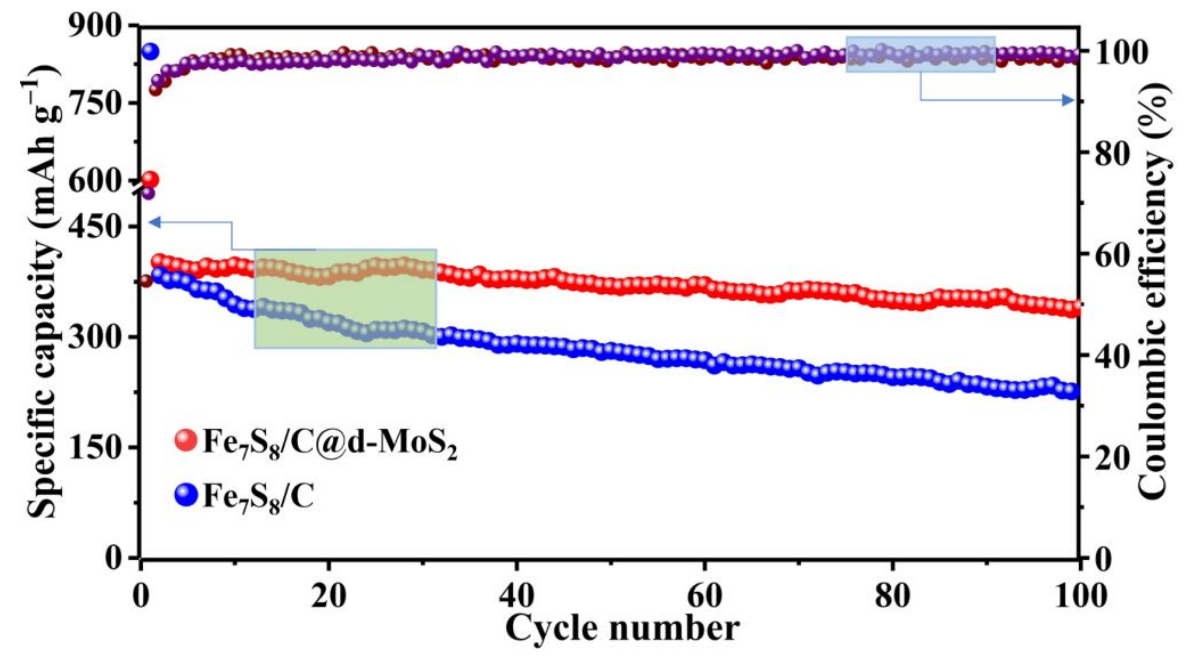

Fig. S14. Cycle performances of $\mathrm{Fe}_{7} \mathrm{~S}_{8} / \mathrm{C} @ \mathrm{~d}-\mathrm{MoS}_{2}$ and $\mathrm{Fe}_{7} \mathrm{~S}_{8} / \mathrm{C}$ in potassium ion batteries with active materials of $1.2 \mathrm{mg} \mathrm{cm}^{-2}$. 

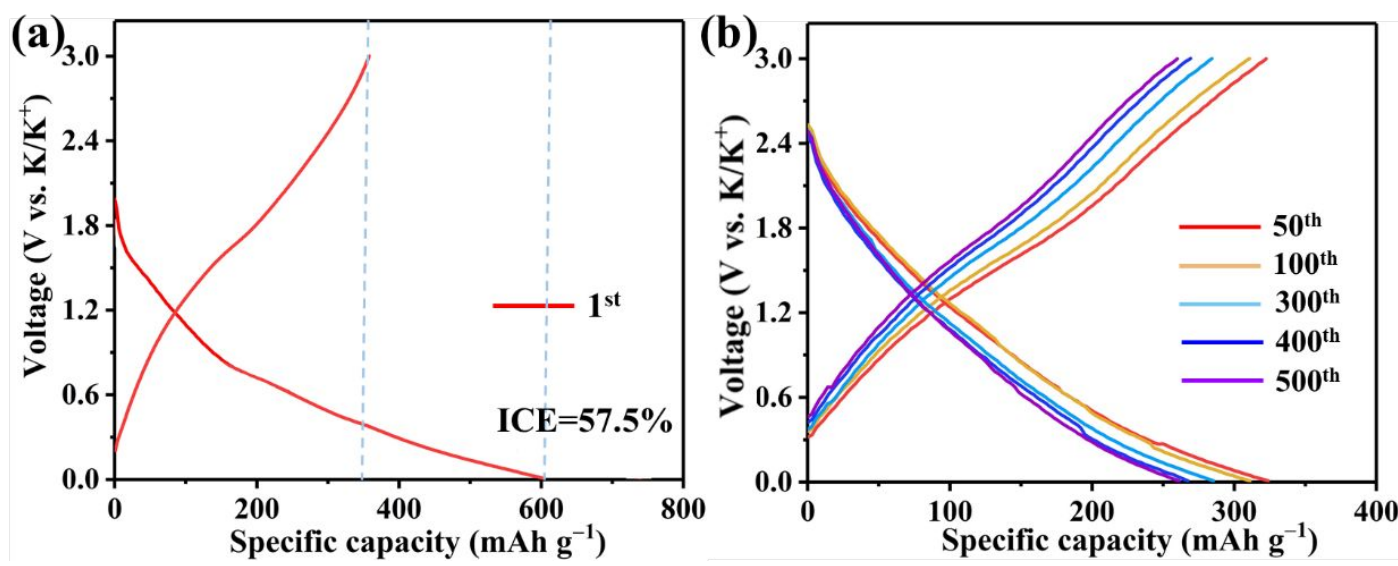

Fig. S15. Initial charge-discharge profiles (a) and the select charge-discharge profiles (b) of $\mathrm{Fe}_{7} \mathrm{~S}_{8} / \mathrm{C} @ \mathrm{~d}-\mathrm{MoS}_{2}$ electrode at a current density of $4.0 \mathrm{~A} \mathrm{~g}^{-1}$.

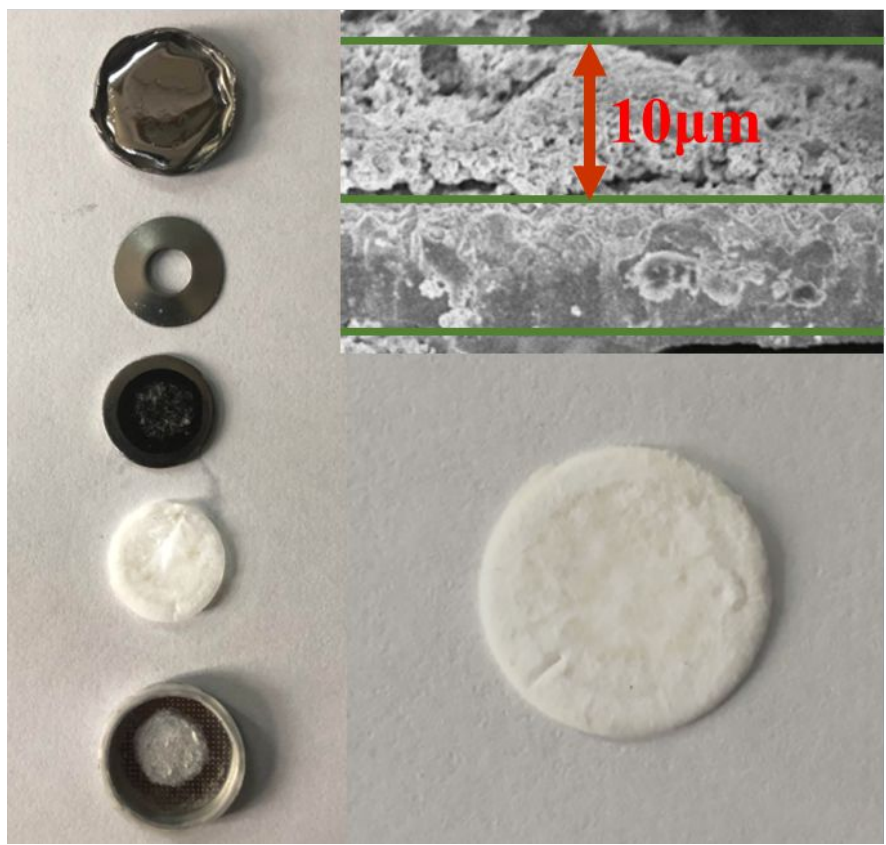

Fig. S16. The digital photo of disassembled cell and the SEM image of electrode after several cycles. 

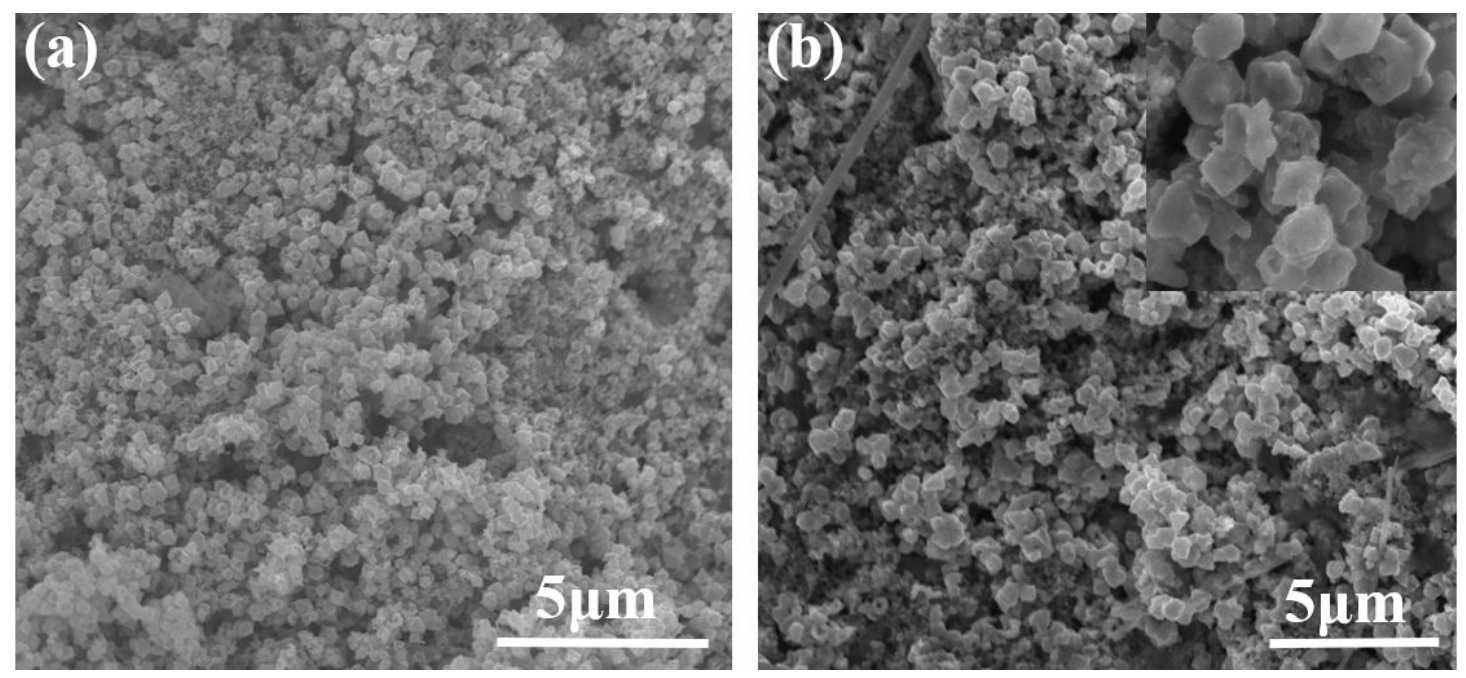

Fig. S17. The SEM image of $\mathrm{Fe}_{7} \mathrm{~S}_{8} / \mathrm{C} @ \mathrm{~d}-\mathrm{MoS}_{2}$ nanocages (a) before and (b) after several cycles.

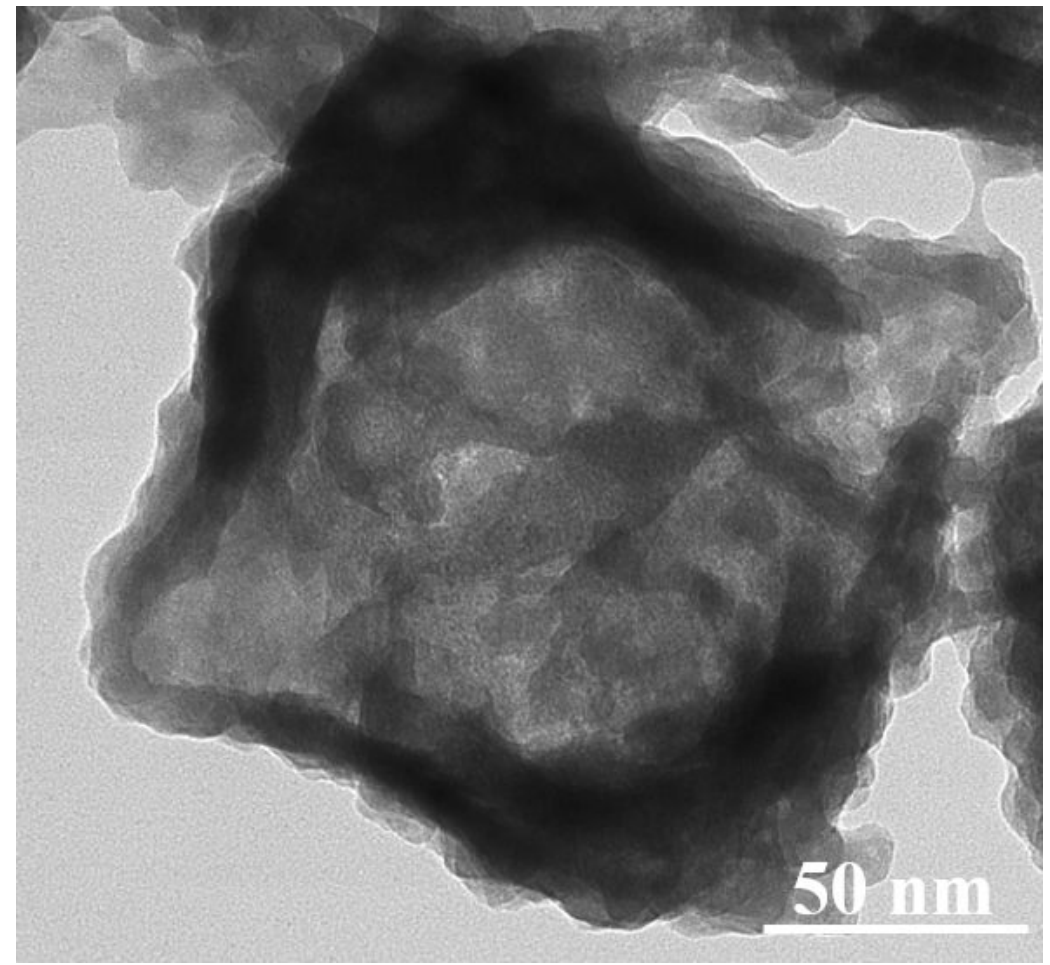

Fig. S18. The TEM image of $\mathrm{Fe}_{7} \mathrm{~S}_{8} / \mathrm{C} @ \mathrm{~d}-\mathrm{MoS}_{2}$ nanocages after cycles. 


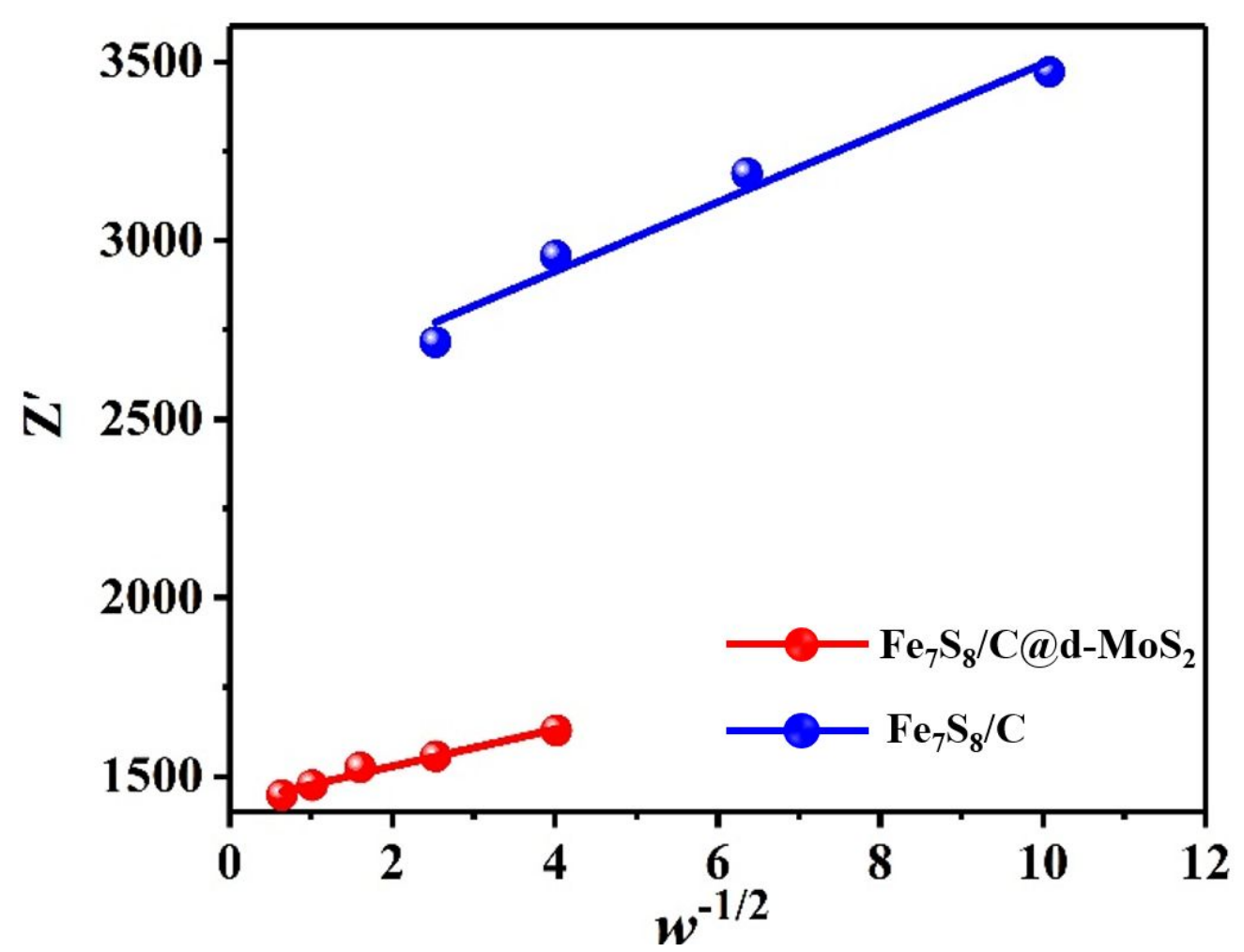

Fig. S19. The relationship between $Z^{\prime}$ versus $\omega^{-1 / 2}$ in the low-frequency region.

Table S2. Electrode kinetic parameters obtained from equivalent circuit fitting of experimental data for $\mathrm{Fe}_{7} \mathrm{~S}_{8} / \mathrm{C} @ \mathrm{~d}-\mathrm{MoS}_{2}$ and $\mathrm{Fe}_{7} \mathrm{~S}_{8} / \mathrm{C}$ electrodes.

\begin{tabular}{|c|c|c|}
\hline Sample & $\boldsymbol{\sigma}$ & $\mathbf{D}_{\mathbf{k}}\left(\mathbf{c m}^{\mathbf{- 2}} \mathbf{s}^{\mathbf{- 1}}\right)$ \\
\hline $\mathbf{F e}_{\mathbf{7}} \mathbf{S}_{\mathbf{8}} / \mathbf{C} @ \mathbf{d}-\mathbf{M o S}_{\mathbf{2}}$ & 54 & $5.43 \times 10^{-9}$ \\
\hline $\mathbf{F e}_{\mathbf{7}} \mathbf{S}_{\mathbf{8}} / \mathbf{C}$ & 96 & $1.78 \times 10^{-9}$ \\
\hline
\end{tabular}




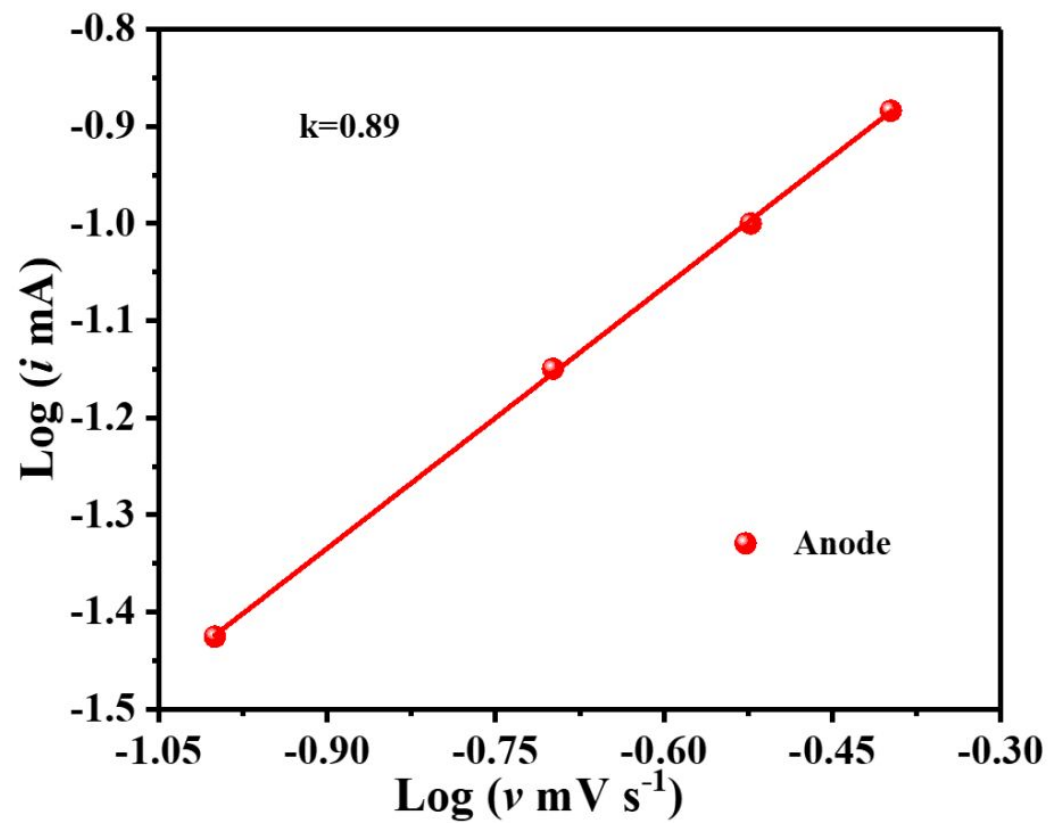

Fig. S20. plots of $\log (\mathrm{i})$ vs. $\log (\mathrm{v})$ at sharp anodic peak pair (peak current: i, scanning rate: $v)$.
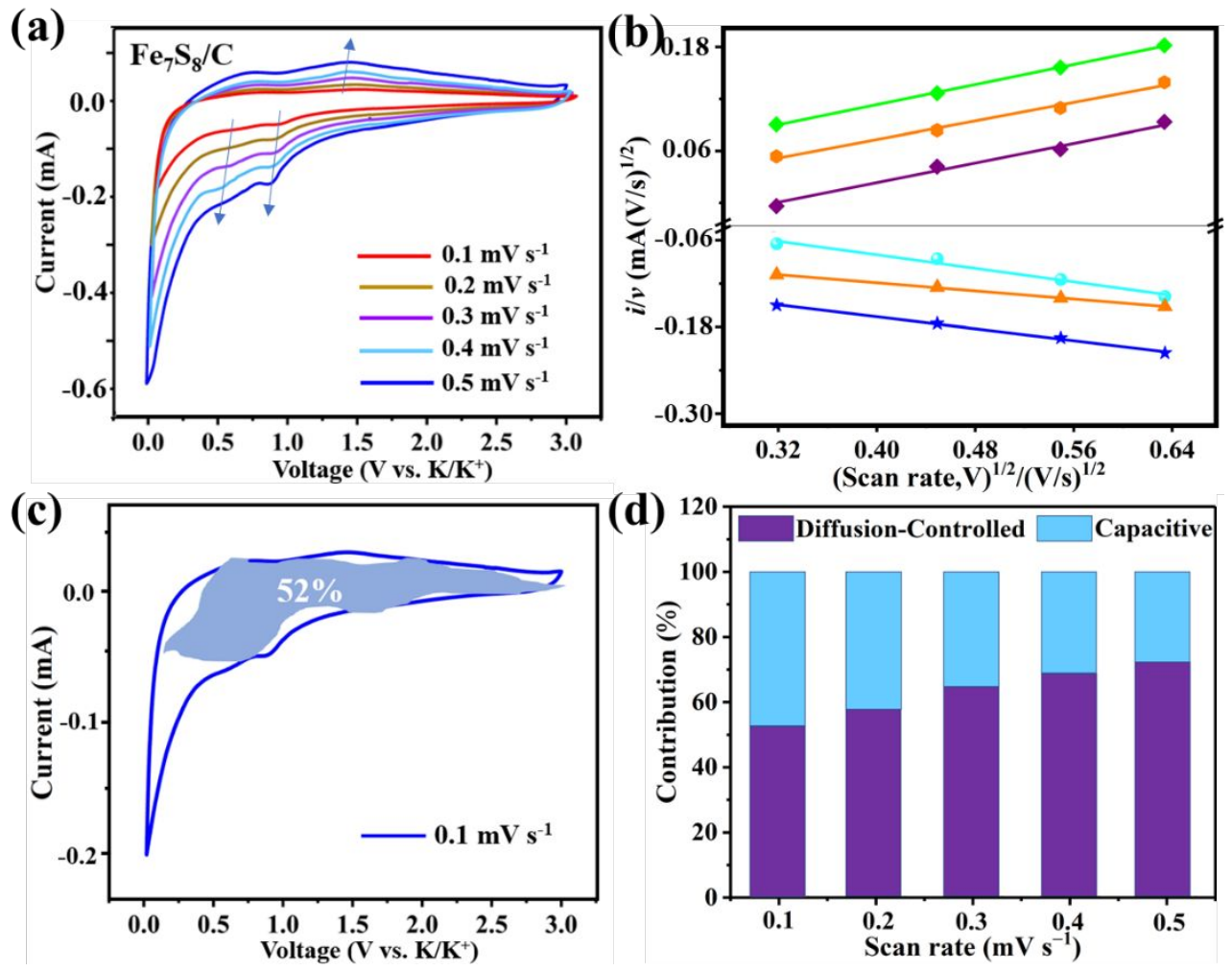
Fig. S21 (a) CV curves of $\mathrm{Fe}_{7} \mathrm{~S}_{8} / \mathrm{C}$ electrode at different scan rates. (b) Plots of $v^{1 / 2} v s$. $\mathrm{I} / \mathrm{v}^{1 / 2}$ used for calculating constants $\mathrm{k}_{1}$ and $\mathrm{k}_{2}$ at different potentials. (c) Capacitive charge storage contribution at a scan rate of $0.1 \mathrm{mV} \mathrm{s}^{-1}$. (d) Relative contribution of the capacitive and diffusion-controlled charge storage at different scan rates.

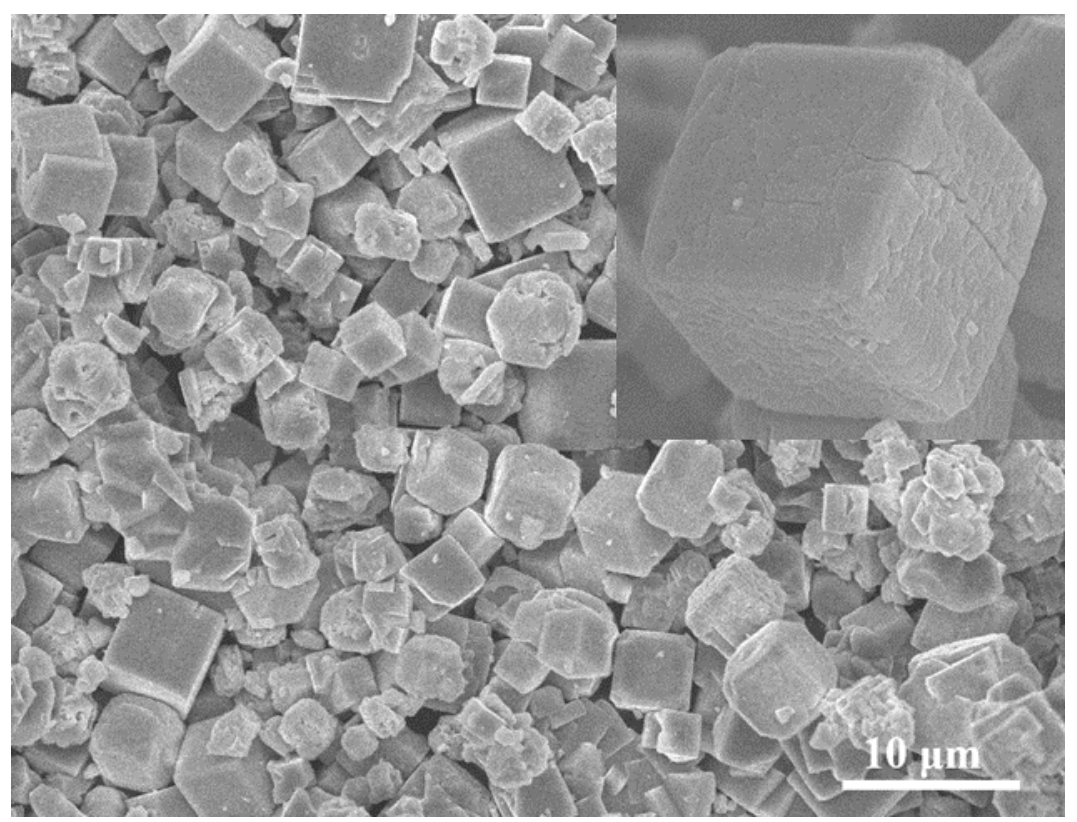

Fig. S22. The SEM image of $\mathrm{K}_{2} \mathrm{Fe}^{\mathrm{III}} \mathrm{Fe}^{\mathrm{II}}(\mathrm{CN})_{6}$ cubes. 